\title{
Dry Peck British
}

National Cancer Institute

\section{Source}

National Cancer Institute. Dry Peck British. NCI Thesaurus. Code C69115.

A traditional (non-SI) unit of volume equal to two British gallons, or approximately 9.09218 liters. 